\title{
0 papel dos tribunais ordinários no âmbito da Convenção da ONU sobre os Direitos das Pessoas com Deficiência: a articulação entre a interpretação pro homine e o controlo de convencionalidade?
}

https://doi.org/10.21814/uminho.ed.30.12

\author{
Filipe Venade de Sousa \\ Professor Convidado na Escola de Lisboa da \\ Faculdade de Direito da Universidade Católica Portuguesa \\ e na Escola Superior de Educação do Instituto Politécnico de Coimbra
}

\section{Introdução}

O presente artigo pretende contribuir, a partir da análise da Convenção das Nações Unidas sobre os Direitos das Pessoas com Deficiência (CDPD) ${ }^{1}$, para as reflexões relevantes acerca da essência do controlo de convencionalidade que surge, essencialmente, como resultado da jurisprudência do Tribunal Interamericano dos Direitos Humanos, especialmente no caso Almonacid Arellano vs. Chile (2006) ${ }^{2}$. Recentemente, o Tribunal Constitucional espanhol tomou em consideração este conceito interamericano explanando-o no alcance das faculdades in casu dos tribunais ordinários, como

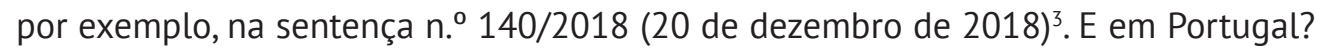
A resposta seria razoavelmente afirmativa. Explicaremos adiante.

10 presente texto foi adaptado com base nos meus estudos desenvolvidos: SOUSA, Filipe Venade de - A Convenção das Nações Unidas sobre os Direitos das Pessoas com deficiência no ordenamento jurídico português: contributo para a compreensão do estatuto jusfundamental. Coimbra: Almedina Editoria, novembro de 2018; "O ius conventionale commune e o controlo de convencionalidade das atuações internas do Estado Parte". in COSTA, Pablo (org.). Controle de convencionalidade, Brasil: Arraes Editores, 2019; A bússola do Direito Constitucional dialógico: atualização e efetividade dos direitos fundamentais. "Revista Católica Law Review, Direito Público", vol. 3, n. ${ }^{0}$ 1, 2019, pp. 13-28; “O controlo de convencionalidade como elemento característico da responsabilidade internacional do Estado". in PEREIRA, Maria de Assunção do Vale (Coord.), Questões de Responsabilidade Internacionais. Braga: Atas da Conferência realização na Escola de Direito da Universidade do Minho no dia 4 de dezembro de 2015. Setembro de 2016, pp. 157-171.

2 Para mais informações, consulte sua jurisprudência. [consultado em 2021-04-23]. Disponível na WWW: <https://www.corteidh.or.cr/CF/jurisprudencia2/ficha_tecnica.cfm?nld_Ficha=335>.

3 Sentencia 140/2018, de 20 de diciembre (BOE núm. 22, de 25 de janeiro de 2019). ECLI:ES:TC:2018:140: “(...) La noción de control de convencionalidad surge formalmente en la jurisprudencia de la Corte Interamericana de Derechos Humanos, en la sentencia de 26 de septiembre de 2006 (asunto Almonacid Arellano y otros c. Chile) (...) Nuestro texto constitucional no contiene previsión expresa alguna relativa a la exigencia de que los jueces ordinarios formulen dicho control de convencionalidad; y tampoco existe esta previsión en relación con el Tribunal Constitucional. Esta ausencia hace preciso verificar si, a pesar de esa constatación inicial, tal control tiene vinculación con algún precepto constitucional y expresa en 


\section{0 significado e função do controlo de convencionalidade}

Para começar, o controlo de convencionalidade é um instrumento idóneo e fundamental para os tribunais nacionais e é um mecanismo jus processual destinado à aferição de compatibilidade das atuações e normas do direito interno, praticadas pelas autoridades nacionais em relação aos tratados internacionais dos direitos humanos, como é exemplo o caso da CDPD. Este controlo implica a existência da obrigação de adequação das autoridades nacionais que devem ter em consideração o corpus iuris da Convenção, por exemplo. A principal finalidade deste controlo é a garantia, efetividade e adequação da observância das atuações estatais em conformidade com o Direito da Convenção, que tem eficácia normativa e interpretativa da tutela dos direitos e liberdades fundamentais.

A pergunta que fazemos é se existe ou não a obrigação das autoridades nacionais de compatibilizar suas atuações à luz da CDPD. Parece-nos que sim. Porquê? Pelo facto de estar prevista a obrigação estatal de que suas atuações nacionais têm de estar em conformidade com a Convenção (cf. art. $4^{\circ} .^{\circ}$ n. ${ }^{\circ} 1$, al. d) da CDPD). Tal acontece, pois, por um lado, a primeira frase do artigo $4 .^{\circ},{ }^{\circ} .^{\circ} 1$, al. d) implica que é uma obrigação estatal de abster a violação das atuações incompatíveis com o Direito da Convenção. Trata-se de um conceito negativo do controlo de convencionalidade. Isso revela que o Direito da Convenção define claramente a obrigação de resultado, i.e., obrigação estatal de respeitar os princípios e as normas estabelecidas pelo Direito da Convenção inerente ao catálogo dos direitos e liberdades fundamentais, mediante adoção de medidas necessárias para assegurar a compatibilidade das suas atuações, sob pena de incorrer na violação da Convenção.

Por seu turno, a segunda frase do mesmo artigo consiste em corresponder a um conceito positivo do controlo de convencionalidade. Isto implica que é uma obrigação de agir em conformidade com a Convenção, mediante a adoção de todas e quaisquer medidas consideradas pertinentes, a fim de assegurar a efetividade da Convenção no ordenamento jurídico nacional. A obrigação de agir em conformidade com a Convenção implica, por um lado, a adoção de medidas necessárias à luz do art. 4. ${ }^{\circ}$ n. ${ }^{\circ} 1$, al. a) e d) da Convenção, nomeadamente, para revogar, modificar ou derrogar as normas e as práticas em geral, incluindo a eliminação de obstáculos ao gozo ou exercício de direitos protegidos, que violem as disposições convencionais pertinentes. Por outro lado, implica a obrigação de garantir que o seu direito interno assegura, efetivamente,

su caso, cuál es el órgano jurisdiccional competente para formularlo y cuál debe ser su alcance.[...] El marco jurídico constitucional existente erige, pues, al control de convencionalidad en el sistema español en una mera regla de selección de derecho aplicable, que corresponde realizar, en cada caso concreto, a los jueces y magistrados de la jurisdicción ordinaria. (...) En suma, el análisis de convencionalidad que tiene cabida en nuestro ordenamiento constitucional no es un juicio de validez de la norma interna o de constitucionalidad mediata de la misma, sino un mero juicio de aplicabilidad de disposiciones normativas; de selección de derecho aplicable, que queda, en principio, extramuros de las competencias del Tribunal Constitucional que podrá, no obstante, y en todo caso por la vía procesal que se pone a su alcance a través del recurso de amparo constitucional, revisar la selección del derecho formulada por los jueces ordinarios en determinadas circunstancias bajo el parámetro del artículo 24.1 CE (...)”. 
o gozo e exercício dos direitos protegidos, bem como, promover práticas que garantem a efetiva observância da Convenção. $O$ Estado Parte tem a obrigação de verificar se o direito interno está ou não conforme à CDPD e, caso esteja desconforme, tem a obrigação de modificar, derrogar ou desaplicar as normas ou atos desconformes. Seja qual for a origem ou a natureza das medidas, deve visar a efetividade dos direitos tutelados pela Convenção, e proceder com vista à sua implementação prática.

A adequação do direito interno conforme a Convenção deve garantir - princípio de effet utile - a efetividade dos direitos tutelados por esta e, sobretudo, o cumprimento pleno, excluindo razões de qualquer natureza teórica ou ilusória invocadas pelo Estado, das suas obrigações de acordo com a mesma. E, ainda, mais importante, o princípio interpretativo pro homine (ou pro personae). A interpretação pro homine da proteção dos direitos e liberdades fundamentais tem como base principiológica 0 artigo $4 .^{\circ}$, n. $^{\circ} 4$ da CDPD. A interpretação do direito interno tem em consideração o Direito da Convenção para complementar e reforçar a tutela judicial dos direitos e liberdades fundamentais das pessoas com deficiência. 0 princípio interpretativo pro homine consiste em afirmar que deve prevalecer a fonte do Direito, interno ou convencional, se se verificar que esta tem um alcance mais protetor e menos restritivo, devendo, pois, proceder-se a um entendimento de cláusula pro homine e não fazendo prevalecer critérios hierárquicos. Dado a especificidade da Convenção, tal como noutros tratados internacionais de direitos humanos, a solução para as antinomias não passa, necessariamente, pela aplicação de um critério hierárquico, mas, sobretudo, pela compatibilização, harmonização e integração dos catálogos dos direitos e liberdades fundamentais.

\section{A função dos tribunais ordinários: aferição de convencionalidade}

\subsection{Considerações gerais}

O art. $204 .^{\circ}$ da Constituição da República Portuguesa tem em consideração a finalidade do artigo $16 .^{\circ}$ da mesma Constituição. Para acompanhar esta lógica, os tribunais ordinários não podem excluir do Direito da Convenção para ter em consideração o catálogo dos direitos e liberdades fundamentais, agindo em conformidade com os princípios e normas da Convenção em virtude do art. $4 .{ }^{\circ},{ }^{\circ} .^{\circ} 1$, al. d) da CDPD. Assim, os tribunais atuam, também, como "juízes de convencionalidade", para estarem vinculados às normas formalmente constitucionais, no sentido de garantir a sua efetividade no ordenamento jurídico português, por meio do exercício da faculdade-dever de aplicar, com base na CDPD, e conjuntamente com a Constituição da República Portuguesa, os "feitos submetidos a julgamento", em virtude do art. 204. ${ }^{\circ}$ da Constituição da República Portuguesa. Nesse sentido, quando o tribunal $a$ quo desaplica uma norma do direito infraconstitucional tendo como fundamento a sua inconvencionalidade, no caso concreto e em particular, com efeitos inter-partes, passando a aplicar a norma da Convenção, ainda é suscetível o recurso ao Tribunal Constitucional para apreciar as questões materiais de inconstitucionalidade (a CDPD 
faz parte da Constituição material), no âmbito recursal do art. $70 .^{\circ}$, al. a) e b) da Lei do Tribunal Constitucional ou através do art. $70 .^{\circ}$, al. i) da Lei do Tribunal Constitucional relativo às questões formais de inconstitucionalidade, i.e., só se pronunciando, sobre as questões formais de vigência e de vinculação das disposições convencionais.

O Tribunal Constitucional tem a função particular de assegurar a eficácia jurídica da Convenção - quanto à efetividade e integridade dos direitos protegidos - nos casos concretos submetidos à fiscalização do Tribunal Constitucional, sobre as decisões de tribunais ordinários que se recusem a aplicar a lei, desconforme com a Convenção. Cabe, sobretudo, ao tribunal a quo, não ao Tribunal Constitucional, resolver as questões "materiais" de inconvencionalidade das normas legais e dos atos que vulnerem os seus direitos protegidos, desaplicando, segundo o art. 204. ${ }^{\circ}$ da CRP, as normas legais contrárias à CDPD.

A interpretação desta norma torna claro que os tribunais ordinários têm o dever de desaplicar as normas incompatíveis com a própria Convenção, respeitando e garantindo os direitos protegidos pela Convenção, devendo aplicar, segundo critérios pro homine, e tendo em conta o objeto e o fim da CDPD, as disposições convencionais nos casos concretos aplicáveis com efeitos inter-partes. Acima de tudo, os juízes nacionais têm o papel de garantia da Convenção, o que implica a faculdade-dever de interpretar e aplicar as normas aplicáveis ao caso concreto secundum conventionanem e não contrario sensu, na medida em que, os juízes nacionais têm a obrigação de desaplicar qualquer disposição interna contrária à CDPD, sob pena de responsabilidade internacional do Estado.

\subsection{O parâmetro de convencionalidade e sua articulação com a Constituição da República Portuguesa}

A própria CRP incorpora o catálogo dos direitos tutelados pela Convenção, assumindo o estatuto materialmente constitucional, fazendo parte do bloco de constitucionalidade. Com efeito, no art. $16 .^{\circ}$, n. ${ }^{\circ} 1$ da Constituição da República Portuguesa, o bloco de constitucionalidade é dialogicamente interativo e horizontalmente constituído por normas formalmente constitucionais e pelo Direito da Convenção. Desta forma, em virtude do art. $16 .^{\circ}$ da Constituição da República Portuguesa, o Tribunal Constitucional pode basear e referenciar as normas da CDPD juntamente com as normas formalmente constitucionais, para fundamentar e declarar a inconstitucionalidade das normas jurídicas ou interpretações normativas que por elas são inconstitucionais, estando a assumir um controlo de convencionalidade de forma complementar a função primária de controlo de constitucionalidade.

Partindo do raciocínio aplicado no exemplo de Acórdão do Tribunal Constitucional n. ${ }^{\circ}$ 352/98, de 12 de maio de 1998, adaptado ao presente objeto de estudo, a CDPD deve ser perspetivada num sentido de aplicação direta, em complemento com as normas da Constituição da República Portuguesa, no ordenamento jurídico nacional, sendo essencial não omitir que as normas formalmente constitucionais não retiraram, em todas as suas vertentes, tanto na dimensão normativa como na dimensão 
interpretativa, o sentido e o alcance que se encontra naquela Convenção. Consequentemente, a própria Convenção acrescenta e revela o sentido e alcance das normas formalmente constitucionais. Tal é fundamental e relevante, pois a Constituição deve assumir, em virtude do art. $16^{\circ}$, n. $^{\circ} 1$ da Constituição da República Portuguesa, o catálogo dos direitos tutelados pela CDPD, por ter força e valor materialmente constitucional, complementando, por meio de integração normativa-interpretativa, o catálogo dos direitos fundamentais constituídos no seio de bloco de constitucionalidade. Sendo que, na apreciação do invocado vício de inconstitucionalidade, necessita o Tribunal Constitucional, e os tribunais ordinários, de apelar e referenciar as normas da CDPD.

A validade das normas infraconstitucionais tem de ser duplamente (e interativamente) verificada em relação à Constituição da República Portuguesa e à CDPD. Caso a norma legal esteja de acordo com as normas formalmente constitucionais, mas não com a CDPD, em virtude do art. $16^{\circ}{ }^{\circ}$, n. ${ }^{\circ} 1$ da CRP, esta não pode ser válida, é materialmente inconstitucional. Tendo em conta o estatuto materialmente constitucional da CDPD, o art. 277. ${ }^{\circ}$, n. ${ }^{\circ} 1$ da Constituição da República Portuguesa exige uma dupla compatibilidade de validade das normas legais - em relação ao bloco de constitucionalidade, incluindo, também, a CDPD. Trata-se de uma questão "material" de inconstitucionalidade, exercendo um controlo de constitucionalidade. A inconvencionalidade de forma complementar é assumida pelo próprio controlo de constitucionalidade, o que significa que tem uma interação dialógica entre a própria Constituição e a CDPD, a nível horizontal, para controlar a constitucionalidade das normas legais.

\section{Conclusões}

A CDPD deve constituir um parâmetro material de constitucionalidade na ordem jurídica portuguesa. Por que os direitos tutelados pela Convenção têm relevância constitucional através do art. $16 .^{\circ}$ da Constituição da República Portuguesa. A extensão do catálogo constitucional de direitos fundamentais complementa-se, mediante garantia de nível de proteção elevadora da fundamentalidade, com "expressão prática" 4 de catálogo dos direitos consagrados pela Convenção, tanto na dimensão normativa como na dimensão interpretativa, como reconhece o Tribunal Constitucional, "o valor heurístico"s dos instrumentos internacionais de direitos humanos "operam como meio complementar de interpretação e desenvolvimento do catálogo constitucional”.

A relevância prática da Convenção é pertinente, por três ordens de razão: em primeiro lugar, o catálogo constitucional de direitos fundamentais complementa-se, devido

\footnotetext{
4 cf. Conferência dos Tribunais Constitucionais Europeus. Relatório de Portugal Direitos Humanos e Liberdades Fundamentais: Catálogos Internacionais, Supranacionais e Nacionais no Século 21 elaborado por Gonçalo de Almeida Ribeiro (Juiz Conselheiro do Tribunal Constitucional), Joana Fernandes Costa (Juíza Conselheira do Tribunal Constitucional) e António Manuel Abrantes (Assessor do Tribunal Constitucional), 2021, p. 5. [consultado em 2021-04-23]. Disponível NA WWW: <https://www.tribunalconstitucional.pt/tc/ content/files/conferencias/ctceu_2021_xviii.pdf>.

5 Idem, p. 5.

6 Idem, p. 11.
} 
especificidades dos direitos das pessoas com deficiência, com o Direito da Convenção que reforça a expressão prática no texto constitucional; em segundo lugar, o catálogo de direitos convencionalmente tutelados reforça a salvaguarda constitucional do catálogo de direitos fundamentais que tem como finalidade a garantia da dignidade da pessoa humana e a igualdade e não discriminação, por exemplo, em virtude do artigo $71 .^{\circ}$ da Constituição da República Portuguesa; em terceiro lugar, tendo em consideração a força jurídica própria da Convenção na ordem jurídica portuguesa em virtude do artigo $16 .^{\circ}$ da Constituição, o Direito da Convenção tem claramente um propósito de contribuir, mesmo com valor "heurístico", ao catálogo constitucional dos direitos fundamentais.

Os tribunais ordinários têm o papel fundamental da garantia do Direito da Convenção; ou seja, têm faculdades pertinentes de cognição em matéria de conformidade do direito ordinário com a Convenção, por exemplo, a alínea i) do art. $70 .^{\circ}$ da Lei do Tribunal Constitucional admite que "a garantia da eficácia das normas convencionais cabe exclusivamente aos tribunais ordinários"7. Trata-se de uma essência norteadora do controlo de convencionalidade.

7 Idem, p. 4. 